\title{
Arsenic and mercury emission from magmatic fluid from active Iwo- yama, Kirishima volcanoes, Japan
}

\author{
MASUdA H. ${ }^{1}$, MORI K. ${ }^{2}$, HABUCHI M. ${ }^{3}$, ISHIBASHI J. ${ }^{4}$, \\ IKAWA R. ${ }^{5}$, TAKEUCHI A. ${ }^{6}$ \\ ${ }^{1}$ Osaka City Univ., harue@sci.osaka-cu.ac.jp \\ ${ }^{2}$ Osaka City Univ., a16sfp0g17@st.osaka-cu.ac.jp \\ 30saka City Univ., habuchi@sci.osaka-cu.ac.jp \\ ${ }^{4}$ Kyushu Univ., ishibashi.junichiro.779@m.kyushu-u.ac.jp \\ ${ }^{5}$ AIST, reo-ikawa@aist.go.jp \\ ${ }^{6}$ NIES, takeuchi.akinori@nies.go.jp
}

Phreatic eruption occurred at Iwo-yama, one of the Kirishima volcanoes in Kyushu, on the $19^{\text {th }}$ April 2018. Strongly acidic saline hydrothermal fluids, of which hydrogen and oxygen isotope ratios were within that of andesite water ( $\delta^{2} \mathrm{H}=-20 \%$ and $\delta^{18} \mathrm{O}=+5 \%$, so-called magmatic water), have been issuing from the two craters. The magmatic fluid contained high concentrations of $\mathrm{As}$ and $\mathrm{Hg}$, giving a chance to observe the direct relation of these element behaviors to volcanic and the associated hydrothermal activities in an arc volcano. Here, these elements in the hydrothermal system have been traced from Jul 2018 to Dec 2019.

The endmember of hydrothermal fluid contained $\mathrm{Cl}^{-}$and $\mathrm{SO}_{4}{ }^{2-}>300 \mathrm{mM}$ and its $\mathrm{pH}$ was $<1$. The highest concetration of total As was $>5 \mathrm{mg} / \mathrm{L}$, and $>90 \%$ was dissolved. The As concetration changed strongly related to the $\mathrm{Cl}^{-}$but not $\mathrm{SO}_{4}{ }^{2-}$ concentration. Arsenite was the primary dissolved species in the deep hydrothermal fluids, and oxidized to arsenate in the shallow part of the subsurface hydrothermal system. Monothioarsenate was synthesized in the hydrothermal pots when the arsenite was reacted with native sulfur.

Dissolved $\mathrm{Hg}$ was $<15 \%$ of the total $\mathrm{Hg}$ for the hydrothermal waters; e. g., total and dissolved $\mathrm{Hg}$ concentrations were 756 and $86 \mathrm{ppt}$ for the hydrothermal fluid taken in Jul 2018. The maximum total $\mathrm{Hg}$ concentration was $>4 \mu \mathrm{g} / \mathrm{L}$ for the water from the same location in Dec 2018 when the magma body slightly ascended. While, the maximum concentration of dissolved $\mathrm{Hg}$ was $0.14 \mu \mathrm{g} / \mathrm{L}$ in the low temperature shallow groundwater taken in Oct 2018, indicating gaseous $\mathrm{Hg}$ was trapped in the ambient shallow and low temperature $\left(\sim 15^{\circ} \mathrm{C}\right)$ groundwater.

Arsenic and $\mathrm{Hg}$ may be originated from dehydrtated slab components and transported int magmatic fluid, similar to $\mathrm{Cl}$, then deseparated in the shallow part of the hydrothermal system. 